\title{
A epidemiologia paisagistica no Brasil
}

\author{
Mário B. Aragão*
}

Existe uma tendência de se considerar a epidemiologia paisagística como uma criação da Escola de Pavlovsky, na década de 1930. Aliás, a obra mais acessível desse parasitologista tem como título "Focos naturais de doenças trans. missíveis. Em relação com a epidemiologia paisagística de zooantroponoses." Galuzo (1975), também soviético, declara: "A concepção de epidemiologia paisagistica tem sua origem no estudo dos focos naturais de doenças."

O glossário da parasitologia de Schmid \& Roberts (1981) registra as seguintes definições:

Epidemiologia. Estudo que se preocupa com todos os aspectos ecológicos das doenças para explicar ou antecipar os surtos das doenças ou sua transmissão, distribuição, preva. lência e incidência.

Epidemiologia paisagística. Enfoque da epidemiologia que utiliza todos os aspectos ecológicos dos focos. Pelo conhecimento de algumas condições físicas, o epidemiologista pode prever onde se pode esperar o aparecimento de uma doença.

Diante dessas definições, parece lícito concluir que o fundador da epidemiologia paisagistica foi Hipócrates com o seu tratado "Ares, Águas e Lugares", onde se preocupava com a situação das cidades em relação ao sol e os ven. tos, se a região tinha o solo desnudo ou arborizado etc.

Não se deve esquecer também que a palavra malária tem uma conotação paisagística. Doença provocada pelo ar de má qualidade, proveniente das regiōes pantanosas.

No Brasil, as primeiras referências confiáveis à influência da paisagem sobre a ocorrência de doenças foram feitas por Oswaldo Cruz, no relatório de 1910 sobre as condiçōes sanitárias do Rio Madeira (Instituto Oswaldo Cruz, 1972). Aí se lê: "O baixo Madeira é tido pelos habitantes da região como rio salubre (. . .) com cerca de 300 portos (. . .) verdadeiras vilas e mesmo cidades (...)". "As Margens do baixo Madeira, contrariamente ao que se nota no Amazonas são relativamente altas e só são alcançadas nas cheias do rio que atingem a 14 metros (. . .)". diferente.

Em relação ao alto Madeira a paisagem descrita é bem

"Naturalmente o regime das águas que inundam as margens baixas do alto Madeira, formando os pântanos donde se originam os aluviôes de mosquitos que se vão encarre-

*Escola Nacional de Saride Pública gar de alastrar a endemia malárica (. . .)". 
Quem conhece a Amazônia sabe que a paisagem muda completamente da época da cheia para a da vazante e isso não passou desapercebido. Assim é que no "Relatório sobre as condições médico-sanitárias do vale do Amazonas", de 1913, Oswaldo Cruz informa: "Começava o período das enchentes tendo então os rios os primeiros repiquetes e nesse momento as epidemias reinantes acham-se em seu mínimo de intensidade (. . .)".

Interessante que, nessa época, Anopheles darlingi transmissor regional da malária era desconhecido da ciência, descrito que foi em 1926.

Passadas quatro décadas, Oliveira Castro (Castro, 1953), trabalhando em Minas Gerais, descreveu, com precisão, o criadouro dessa espécie.

"De avião observamos a geomorfologia e, in loco, os criadouros de Anopheles (Nyssorhynchus) darlingi, espécie particularmente visada. Há em comum o vale com várzea de inundação, meandros abandonados pelo rio e, exceto Fama, condiçôes naturais suficientemente preservadas para que criadouros de mosquitos mostrem grande parte do aspecto primitivo."

Curioso que esse aspecto primitivo já havia permitido ao Dr. Abel Vargas, médico da Light e primeiro diretor do Serviço Nacional de Malária, fazer a primeira aplicação prática da epidemiologia paisagística aqui no Brasil (Vargas \& Savelli, 1949).

Quem viaja pela rodovia Rio-São Paulo, nota, depois da passagem do tope da Serra do Mar, a represa de Ribeirão das Lages com as margens completamente despidas de vegetação. $\mathrm{E}$ que $A$. darlingi é um mosquito heliófobo e essa característica foi a proveitada em todas as represas da Light. Em São Paulo a área a ser inundada pela represa Billings foi totalmente desmatada antes de seu fechamento. Infelizmente esse cuidado tem sido esquecido em algumas grandes represas construídas no país.

No trabalho, já citado, de Vargas \& Savelli observase que a Light fazia um verdadeiro relatório de impacto antes da construção de qualquer obra.

Depois desses pioneiros apareceram alguns trabalhos de uma nova geração, hoje já não tão nova, desenvolvida sob a influência do Prof. Samuel Pessoa que, numa determinada época, esteve interessado em estimular jovens para o estudo da Geografia Médica (Pessoa, 1978).

Deane (1956) quando trabalhou no Pará, no grupo de Evandro Chagas, já havia observado que a leishmaniose visceral só ocorria nas matas de terra firme e nunca nas de várzea. Ao ser encarregado de estudar essa endemia no Ceará definiu, com precisão, as áreas de maior incidencia da doença. São os boqueirōes e os pés de serra, isto é, áreas 
situadas entre serras ou na periferia delas. Outra característica era os terrenos serem pedregosos. Aliás o transmissor, Lutzomvia longipalpis, é um flebótomo encontradiço onde há afloramentos rochosos. Foge a essa regra o baixo vale do rio Jaguaribe, no Ceará, onde a doença se manifesta no leito maior do rio.

Aragão (1964) estudando os anofelinos do subgênero Kerteszia, chama a atenção para o fato desses mosquitos existirem em densidades muito altas, capazes de propiciar transmissão de malária, no trecho da fachada sudeste do país onde a nebulosidade é a mais elevada. A circulação atmosférica e o relevo permitem explicar esse fato.

$\mathrm{O}$ trecho onde a malária era mais intensa, que vai da divisa de São Paulo com o Paraná, até um pouco ao sul de Florianópolis, visto num mapa de relevo, se apresenta como uma série de anfiteatros todos voltados para leste ou para nordeste e arrumados dentro de um outro maior, formado pelas serras do Mar e Geral. Nessas condições os ventos de nordeste, predominantes nessa latitude, são ascendentes até a escarpa do planalto. Ai, as frentes que acarretam chuvas têm seu avanço retardado e mantêm a nebulosidade observada depois das precipitaçōes. No inverno, quando se instalam na região massas de ar polar, que são muito limpidas, o forte resfriamento noturno provoca a formação de grande quantidade de orvalho que, também, beneficia as bromeliáceas que são criadouros desses anofelinos.

Aproveitando os mapas temáticos do Projeto RADAM Aragão (1987) mostrou os tipos de paisagem em que ocorrem algumas endemias no Estado do Pará.

Esses mapas do Projeto RADAM, hoje cobrindo todo o território brasileiro precisam ser aproveitados pelos epidemiologistas. Eles permitem a confecção do que Rodenwaldt \& Jusatz (1956) chamam de mapas de prognóstico. São mapas com representação dos fatores geográficos mais importantes, por exemplo, relevo, vegetação, divisões zoogeográficas, chuva, temperatura etc, desde que esses fatores tenham importância sobre a dispersão das doenças ou de seus vetores.

Plagiando o Padre Jesus Moure, notável entomologista do Paraná, que sempre diz para seus alunos: "é preciso olhar para os bichos", queremos terminar com um recado para os jovens epidemiologistas: é preciso olhar para a paisagem.

\section{REFERENCIAS BIBLIOGRÁFICAS}

ARAGĀO, M. B. Distribuição geográfica e a abundância das espé- 
cies de Anopheles (Kerteszia). Rev. Bras. Malar. D. Trop., 16: 73-109, 1964.

ARAGÃO, M. B. As endemias rurais na Folha SA. 22 Belém, do Projeto RADAM. Cad. Saúde Publ., Rio de Janeiro, em publicação.

CASTTRO, G. M. O. Estudo ecológico de mosquitos no vale do Jequitaí. Rev. Bras. halar. D. Trop., 5: 75-78, 1953.

DEANE, L. M. Leshmaniose visceral no Brasil. Rio de Janeiro, Serviço Nacional de Educação Sanitária, 1956.

GALUZO, I. G. Landscape epidemiology (Epizootiology). Advances in Veterinary Science and Comparative Medicine, 19: 73-76, 1975.

INSTITUTO OSWALDO CRUZ, Oswaldo Gonçalves Cruz, Opera Omnia (Org. por E. Bustamsnte), Rio de Janeiro, 1972.

PAVLOVSKI, E. N. s.d. - Natural nidality of transmissible diseases. Peace Publishers. Moscou.

PESSOA, S. B. Ensaios médico-sociais. 2a edição, São Paulo, CEBES, Hucitec, 1978.

RODENWALDT, E. \& JUSATZ, H. J. Methods of mapping the distribution, spread and development of epidemic diseases. In: Eighteenth International Geographical Congress. Abstracts of Papers, Rio de Janeiro, 1956.

SCHMIDT, G. D. \& ROBERTS, L. S. Foundations of parasitology. Second edition. St. Louis, The C. V. Mosby Company, 1981.

VARGAS, A. \& SAVELLI, M. Armazenamento d'água e malária. Rev. Bras. Malar., 1: 242-262, 1949. 